\section{$\underset{\substack{\text { hommes } \\ \text { \& migrations }}}{ }$}

\section{Hommes \& migrations}

Revue française de référence sur les dynamiques

migratoires

$1324 \mid 2019$

Religion et discrimination

\title{
Boualem Sansal, Le Train d'Erlingen ou La métamorphose de Dieu
}

Gallimard 2018, 248 p., $20 €$

\section{Mustapha Harzoune}

\section{(2) OpenEdition}

Journals

Édition électronique

URL : https://journals.openedition.org/hommesmigrations/8707

DOI : 10.4000/hommesmigrations.8707

ISSN : 2262-3353

Éditeur

Musée national de l'histoire de l'immigration

Édition imprimée

Date de publication : 1 janvier 2019

Pagination : 223-224

ISBN : 978-2-919040-44-5

ISSN : 1142-852X

Référence électronique

Mustapha Harzoune, «Boualem Sansal, Le Train d'Erlingen ou La métamorphose de Dieu », Hommes \& migrations [En ligne], 1324 | 2019, mis en ligne le 01 janvier 2019, consulté le 08 janvier 2022. URL : http://journals.openedition.org/hommesmigrations/8707 ; DOI : https://doi.org/10.4000/ hommesmigrations.8707 


\section{Le train d'Erlingen} ou La métamorphose de Dieu

Boualem Sansal, Paris, Gallimard, 2018, 256 pages, 20 euros.

Voici le nouveau Sansal! Comme souvent, la sortie d'un de ses romans ne laisse pas indifférent: 


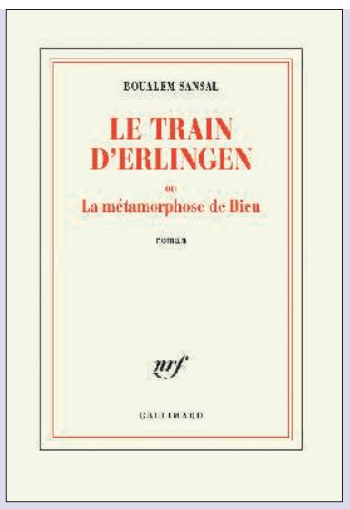

louanges ou détestations déchirent le Landerneau. D'année en année, deux camps se toisent. Les uns éreintent le livre (David Caviglioli dans L'Obs), les autres encensent la vigie de Boumerdès (Félicia-France Doumayrenc sur actuallite.com ou l'excellent Achour Wamara sur exilience.fr). Les uns taisent ce qui dérange, les autres en rajoutent sur ce qui arrange. Sous l'instrumentalisation, la littérature étouffe. De l'écrivain, ne reste que des caricatures. Même s'il ne rechigne pas à faire son office médiatique, il n'est pas certain que l'humble Sansal en demande autant. Aussi, plutôt que de céder à la faiblesse qui veut le critique omniscient, un brin donneur de leçons à défaut de distiller de l'information, il faut ici tenter une expérience. Plutôt que de rendre compte de ce livre, avec une pertinence relative, tentons d'exciter curiosité et réflexion par quelques questions (la liste n'est pas exhaustive) soulevées par ce récit protéiforme, volontairement (sans doute) déstabilisant. Il faut bien que l'écrivain instrumentalisé rende la monnaie de leur pièce aux ventriloques et à ce qu'ils croient être leur marionnette.

Petit résumé pour repère:

Élisabeth Potier, professeur d'histoire dans un lycée de banlieue à la retraite, victime collatérale des attentats de novembre 2015, se réveille (invente) Ute Von Ebert, richissime héritière retirée à Erlingen. Plutôt coincée, car la ville, qui patauge dans «l'essentiel et le superflu», «le défendu et le nuisible», «l'ennui» même et la misère postindustrielle, est sous la menace d'«envahisseurs» invisibles et semeurs de mort. Chacun attend l'arrivée d'un train miracle pour s'esbigner et abandonner la cité. Élisabeth, alias Ute, destine à sa fille des lettres, des notes de lectures et un roman inachevé qui consigne les micmacs de cette ville assiégée et l'histoire de la famille Ebert. Tout est fiction, et la mort d'Élisabeth sonne la fin de la «fantasmagorie». Retour au réel, Erlingen s'efface pour une bonne vieille cité de banlieue et la découverte, par sa fille, des travaux d'écriture maternels. À elle de finir le boulot. La construction du roman déroute, mais la vérité, suggère l'auteur, n'est pas une rectiligne avenue à sens unique (malgré les modes, les faiblesses et les coups de trique), et la langue de Sansal confirme qu'il est et reste un des grands écrivains contemporains, manieur de plume, de mots, d'images hors pair. Et si Sansal se jouait de ses lecteurs par trop idéologiques en les perdant dans les méandres de la fiction et du réel, dans les détours d'une construction baroque où se cache sa part de vérité qu'il veut croire être aussi la nôtre? Alors questionnons, histoire de ne pas réduire la lecture à un règlement de compte à Ok Corral. Ainsi, pourquoi situer ce récit en Allemagne, à Erlingen, imaginaire et paisible ville européenne? Que disent Erlingen et sa société de la modernité, du «vivre ensemble», des édiles et des démocraties où «l'administré» remplace «le peuple»? Pourquoi ce train qui fait paradoxalement penser aux trains de la mort? Pourquoi réincarner Élisabeth en une héritière d'un empire construit par un colon «négrier chez les Indiens» (" le seul moteur de l'humanité est le vol et l'escroquerie» disait Cossery)? Que disent de la littérature ces jeux entre fiction et réalité, ces dédoublements, ces allers-retours dans le temps, ces mises en abîme des textes? D'ailleurs, Sansal a-t-il écrit un roman ou cède-t-il à son «obsession» islamiste? Pourquoi alors convoquer Baudelaire et son "que cherchent-ils au Ciel, tous ces aveugles?»? Que viennent faire Kafka, Thoreau, Buzzati ou ce Traité des trois imposteurs, Moïse, Jésus, Mahomet? De quelles métamorphoses est-il question? Et cetera, et cetera.

Mustapha Harzoune 